\title{
Mídia-educação: da criatividade à livre expressão na escola*
}

Roseane Andrelo

Doutora em Educação Escolar pela Unesp de Araraquara e professora da Universidade Estadual Paulista (Unesp) - campus Bauru.

E-mail: randrelo@terra.com.br

Marcele Tonelli de Oliveira

Formada em Comunicação Social - habilitação em Jornalismo pela Universidade Sagrado Coração e bolsista de Iniciação Científica da Fundação de Amparo à Pesquisa do Estado de São Paulo (Fapesp), durante o ano de 2010.

E-mail: marceletonelli@hotmail.com

Resumo: Com o advento das mídias e da cultura de massa, ações de mídia-educação tornam-se cada vez mais necessárias no contexto da escola. O presente artigo resulta de uma Iniciação Científica realizada com alunos do Ensino Médio público. A pesquisa teve como objetivo a construção de metodologias que exercitassem a leitura crítica das mídias e estimulassem a produção de conteúdos criativos utilizando as linguagens do som e da imagem. Para isso, foram realizadas oficinas de rádio e fotografia. Os resultados das análises obtidas mostraram que os estudantes, apesar de serem alvo de um aprendizado acrítico e passivo, possuem grande capacidade de expressão e potencial criativo, quando são instigados a falar sobre algo por meio das linguagens midiáticas.

Palavras-chave: Mídia-educação, música, fotografia, jovens, criatividade.
Abstract: With the advent of media and mass culture, media education actions become increasingly necessary within the school. This paper is the result of an Undergraduate Research conducted with high school students and public. The survey was aimed at building methodologies who exercised a critical reading of media and stimulate the production of creative content using the language of sound and image. To this end, workshops were held radio and photography. The analysis results obtained showed that students, despite being the targets of an uncritical and passive learning, great ability and potential for creative expression when they are encouraged to talk about something through the media languages.

Keywords: Media education, music, photography, youth, creativity.

\section{INTRODUÇÃO}

O presente artigo é resultado de uma pesquisa, financiada pela Fapesp, que propôs explorar o uso do som, da imagem e do texto para o teste e a elaboração de metodologias de mídia-educação para o Ensino Médio público. As atividades propostas combinaram as linguagens do rádio e da fotografia na produção de mensagens criativas. A abordagem consistiu em trabalhar, por

Recebido: 26/05/2011

Aprovado: 21/10/2011

* Este artigo é resultado de um projeto de Iniciação Científica financiado pela Fundação de Amparo à Pesquisa (Fapesp), durante o ano de 2010. 
comunicação \& educação • Ano XVII • número 1 • jan/jun 2012

meio de oficinas, atividades com elementos como reconhecimento, percepção e análise de músicas, imagens e textos, explorando as características individuais desses recursos e também a sua relação nas produções midiáticas. Como produto final, os alunos elaboraram um programa radiofônico e posteriormente uma fotoestória. Para publicação e junção das linguagens utilizadas, foi explorado o potencial da plataforma Mypace.

Os resultados mostraram que os estudantes possuem grande capacidade de expressão e potencial criativo, quando são instigados a falar sobre algo através das linguagens midiáticas, bem como capacidade de compreensão sobre o processo de manipulação dos meios. A pesquisa também mostrou que a criatividade e a liberdade de criação possibilitam aos jovens um aprendizado além da reprodução e subordinação criativa pregadas pela atual configuração do currículo escolar e do sistema de ensino, que transformam o aluno em agente passivo de seu próprio aprendizado.

\section{RAZÕES DA MÍDIA-EDUCAÇÃO}

A mídia-educação, ou Media Literacy, como é chamada na visão inglesa, é conceituada como as atividades capazes de desenvolver nos cidadãos habilidades específicas para acessar, analisar, produzir informação, ter capacidade de argumentar e saber como influenciar leitores ativos das mídias, a fim de torná-los cidadãos mais participativos, críticos e conscientes.

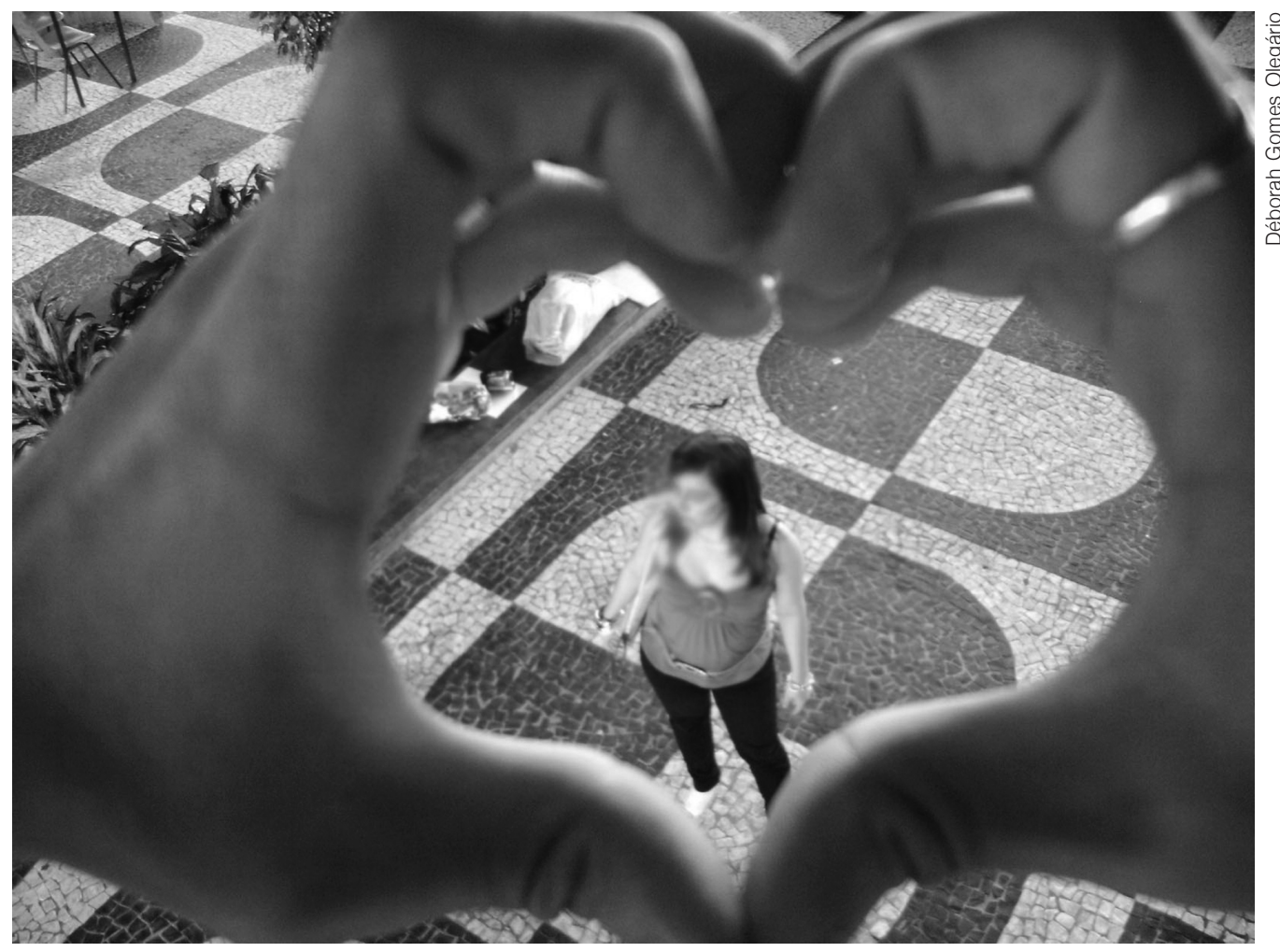

Alunos usam a criatividade e conceitos aprendidos para produzir vídeo. 
Razões que demonstrem a importância da mídia-educação são relativamente fáceis de ser sistematizadas, principalmente por causa do caráter de obviedade dessa necessidade: a mídia ocupa lugar central na cultura jovem, as mensagens midiáticas não são transparentes e, logo, é preciso que o leitor tenha um referencial crítico para tirar proveito dessas mensagens - não só como consumidores, mas também como cidadãos ${ }^{1}$.

Como aponta Siqueira ${ }^{2}$, o objetivo da educação para mídia, ou mídia-educação, não é levar os jovens a romperem o consumo dos bens ofertados pela indústria cultural e direcioná-los para a "apreciação da alta cultura, para comportamentos moralmente saudáveis, para crenças mais racionais e politizadas" ${ }^{\prime}$, mas sim prepará-los para o desenvolvimento de uma referência crítica sobre seus próprios gostos, consumindo de modo mais consciente esses produtos.

Neste contexto, salienta-se a importância de estratégias que sejam capazes de desenvolver no jovem uma aproximação com o aprendizado multimodal para a exploração do universo de sentidos constituído em sua realidade. Um exame dos estudos sobre mídia, particularmente música e fotografia, mostra que há um fértil terreno a ser explorado na escola.

\section{A MÚSICA E AS INFLUÊNCIAS DO MERCADO}

O campo das composições audiovisuais tornou-se, ao longo dos anos, o foco principal da circulação de sentidos e símbolos da convencionada "cultura de massa”. Estudos recentes comprovam um amplo espaço de pesquisa da cultura jovem aplicada sobre a música.

Segundo Trotta ${ }^{4}$, ouvir música é um ato simbólico que demonstra a identificação com as representações de estilos de vida, visões de mundo e valores sociais presentes nas canções. "Participar de uma experiência musical significa entrar em contato com esses códigos culturais, valores sociais e sentimentos compartilhados que fornecem elementos para a construção de identidades sociais e laços afetivos" ${ }^{2}$.

A sonoridade envolve imaginação e afetividade, atingindo profundamente a emoção. Os jovens, principalmente, costumam ouvir canções com "corpo e alma", identificando-se com o modo de se vestir, as coreografias, as luzes, as cores, os gestos e os textos que envolvem a música.

Segundo Didoné e Soares ${ }^{6}$, o sistema social da atualidade, cercado pela desigualdade entre classes e a dominação de uma minoria da população sobre o todo, é mantido através de estratégias que garantem privilégios a alguns, principalmente por meio dos meios de comunicação de massa. Nesse ocultamento de diferenças sociais é que se expande a ideia de homogeneização, que, no caso, é responsável por transformar a diversidade sociocultural dos diferentes segmentos da juventude e a variedade de gêneros em uma coisa só, formatada aos moldes do mercado - ou seja, em um mero produto. Seguindo este mesmo raciocínio, os autores formulam um questionamento a respeito das "fórmulas de sucesso" como uma questão de agendamento da mídia. "É a sensibilidade, gosto musical
1. BUCKINGHAM, David. The media literacy of children and young people: a review of the research literature on behalf of Ofcom [A media literacy de crianças e jovens: uma revisão da literatura de pesquisa em behalf of Ofcom]. Londres: Office of Communications, 2005. p. 123. BUCKINGHAM, David. Media education: literacy, learning and contemporary culture [Educação mediática: literatura, aprendizado e cultura contemporânea]. Cambridge: Polity Press, 2003.

2. SIQUEIRA, Alexandra. Educação para a mídia: da inoculação à preparação. Educação \& Sociedade, Campinas, vol. 29, n. 105 p. 1043-1066, set./dez. 2008.

3. Ibid., p. 1053.

4. TROTTA, Felipe. Música e mercado: a força das classificações. Contemporânea - Journal of Communication and Culture, v. 3, n. 2, 2006.

5. Ibid., p. 183.

6. DIDONÉ, Iraci M.; SOARES, Ismar O. O jovem e a comunicação. São Paulo: Edições Loyola, 1992. 
comunicação \& educação • Ano XVII • número 1 • jan/jun 2012

dos ouvintes que determina o estilo musical evidenciado, ou o modelo musical veiculado pelos meios de comunicação que determina a preferência do público?"7

\section{LEITURA CRÍTICA}

Para estabelecer a consciência nos jovens acerca dos processos de influência gerados pela indústria cultural através dos meios de comunicação, é preciso que haja uma reflexão crítica, ou seja, uma leitura crítica das mensagens e da linguagem dos meios.

Caldas $^{8}$ defende a necessidade de um trabalho integrado entre educadores e jornalistas, afirmando que a leitura crítica é algo que deve ser trabalhado em contato direto com as linguagens dos meios, observando suas múltiplas possibilidades e compreendendo sua produção, suas armadilhas e seus limites.

A criticidade possibilita o descobrimento de nuances e intenções que identifiquem os valores omitidos e os níveis de subordinação e influência dos conteúdos exibidos na mídia e nos veículos em geral. Ela acontece, portanto, através de uma avaliação que permite enxergar o sistema e o código de comunicação de um produto cultural que pode ser reformado ou reformulado a partir de um segmento ou ideologia.

\section{EDUCAÇÃO MUSICAL}

Diante do exposto, a educação musical almeja contribuir com a formação crítica, promovendo reflexões em torno do universo de consumo jovem, ajudando na quebra de preconceitos e ensinando novos caminhos para a apreciação de produtos musicais.

Em seu livro $O$ ouvido pensante, Schafer ${ }^{9}$ relata uma série de práticas realizadas com estudantes, por meio das quais o autor desenvolve diálogos e questionamentos para despertar o interesse dos alunos. Schafer ${ }^{10}$ desmistifica o significado de ruído, aponta as características do som e atribui particularidades e virtudes na utilização do silêncio nas composições. Uma questão levantada é: o que qualificaria uma música como boa ou ruim? A partir daí, expõem-se diversas questões, demonstrando aos alunos que a música pode ser ruído se realizada de maneira indesejada, assim como o ruído pode ser música ao ser intencional e possuir uma organização. Ele acredita que o primeiro elemento a

7. Ibid., p. 66.

8. CALDAS, Graça. Mídia, escola e leitura crítica do mundo. Educação \& Sociedade, Campinas, v. 27 , n. 94 , p. $117-130$, jan./ abr. 2006.

9. SCHAFER, R. Murray. $\mathrm{O}$ ouvido pensante. São Paulo: Fundação Editora da Unesp, 1991.

10. Ibid., p. 68. ser trabalhado em relação à educação musical é a percepção sonora, ou, como ele mesmo propõe, a "limpeza de ouvidos", para estimular os jovens a ouvirem o som à sua volta com maior atenção e sensibilidade.

\section{O RÁDIO NA EDUCAÇÃO}

Para a realização de tais atividades, sejam elas musicais, sejam ligadas à própria linguagem da mídia, é preciso contar com a ajuda do rádio. Afinal, além de ser um meio de comunicação abrangente e popular, sua linguagem 
engloba o uso da reflexão crítica do som, da música, do texto, da voz humana, dos efeitos sonoros e do silêncio.

Em sua tese de doutorado, Andrelo ${ }^{11}$ descreve experiências que elegem o rádio como instrumento facilitador do ensino. A autora afirma que, ao ser utilizado com propósitos educativos, o veículo possibilita o desenvolvimento da imaginação e abre espaço à criatividade por suas ricas possibilidades de produção. Além disso, trata-se de um instrumento de aprendizado "transdisciplinar", desenvolvendo a expressão oral dos jovens, integração, capacidade de pesquisa, progressão da própria escrita através da elaboração de roteiros e o despertar de responsabilidades, além de diversos outros benefícios.

\section{A IMAGEM E OS ÍDOLOS}

Além do som, o estudo com a imagem também é fundamental para uma reflexão mais aprofundada a respeito dos produtos midiáticos. A fotografia é passível de culturas e ideologias e o processo fotográfico é uma forma de extensão da própria vida do observador.

Nas concepções de Tacca $^{12}$, as imagens são responsáveis pela construção e desconstrução dos ídolos de consumo de massa nas sociedades capitalistas. Exemplificando essa transformação, Kossoy ${ }^{13}$ cita que, na foto de moda, "[...] consomem-se ao mesmo tempo dois produtos que se mesclam num todo indivisível: o vestuário propriamente dito e o seu entorno, mundo ficcional que envolve a cena, a situação, a pose, o gesto"14. Nesse processo percebe-se que há um consumo não somente do produto, mas de um estilo, uma estética de vida codificada no conteúdo da representação, no qual estão implícitos o script e o estúdio, resultando na adoção de determinado comportamento pelo público na realidade concreta.

Tomando como base os estudos relacionados com a música e o mercado fonográfico, pode-se fazer uma análise comparativa entre as fotos de moda e as imagens dos ídolos musicais consumidas pelos jovens hoje. A imagem dos ídolos musicais é normalmente apropriada de modo a ditar determinadas características e estereótipos. Ao seguirem o estilo determinado, os jovens se sentem, de certa forma, acolhidos por um seguimento ou uma tribo. Portanto, antes de deixá-los à mercê de um mercado de bens culturais massificados e padronizados, é preciso apontar os caminhos que poderão levá-los a uma reflexão alternativa, traçados através da desconstrução de imagens e da compreensão das estratégias de produção do universo fotográfico.

\section{A PESQUISA}

A metodologia foi constituída em quatro etapas:

1. A partir do conhecimento adquirido com as bibliografias, foram formatadas as atividades e produzido o material, focado na produção de mensagens utilizando fotos, música e texto. Foram também realizados alguns exercícios por meio da plataforma digital Myspace ${ }^{15}$.
11. ANDRELO, Roseane. Política educacional e as tecnologias de informação e comunicação: o rádio na educação escolar. Tese de doutoramento, Unesp Bauru, São Paulo, 2008.

12. TACCA, Fernando de. Imagem fotográfica: aparelho, representação e significação. Psicol. Soc. [on-line], v. 17, n. 3, 2005.

13. KOSSOY, Boris. Realidades e ficções na trama fotográfica. Cotia, São Paulo: Ed. Ateliê Editorial, 1999.

14. Ibid., p. 52.

15. Disponível em: <http://www.myspace. com>. 
comunicação \& educação • Ano XVII • número 1 • jan/jun 2012

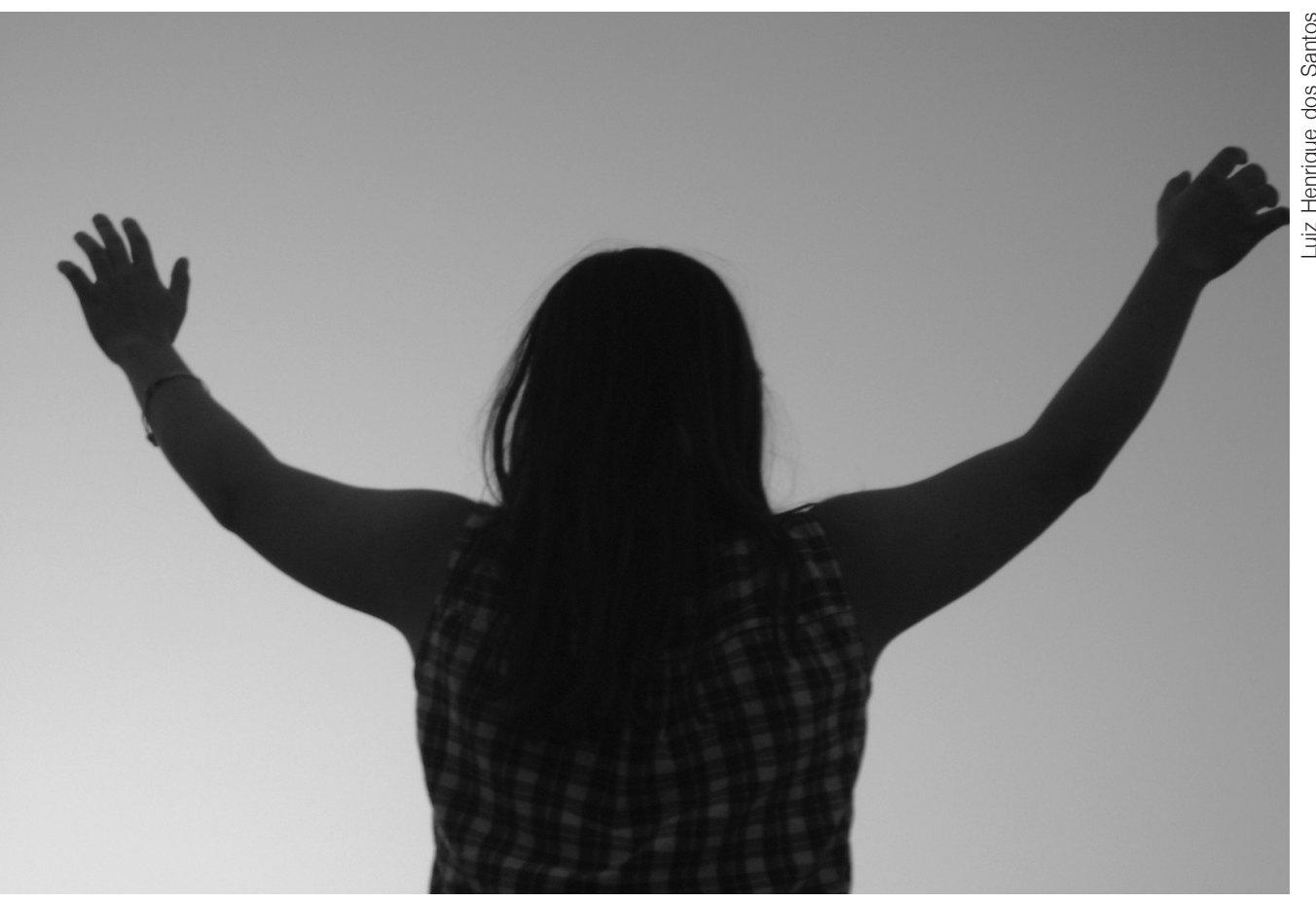

Cena de fotoestória produzida pelos alunos.

2. O material foi testado em oficinas realizadas junto a estudantes do Ensino Médio público. A aplicação do conteúdo das oficinas consistiu em seis etapas:

I - Inicialmente foi proposta uma atividade de reconhecimento dos sons ambientes e da distinção entre as definições de som, silêncio e ruído na concepção dos jovens. Posteriormente, foi realizada uma atividade que mostrou o papel do som na alteração de significados e na atribuição de sentidos às situações. Esses exercícios foram úteis para a introdução aos conceitos de sonoplastia.

II - O segundo passo foi a aplicação de um formulário que permitiu identificar as preferências musicais dos alunos, demonstrando em que medida houve interferência da mídia nestas preferências. O reconhecimento de algumas características musicais, tais como a presença de instrumentos, voz, arranjos, melodia e letra, também foram trabalhadas nessa etapa, com foco na produção de uma pequena análise sobre as músicas de que eles mais gostavam.

III - A terceira etapa foi a discussão de questões presentes na rotina das emissoras de rádio, como, por exemplo, o "jabá"16 versus a condição de concessão pública; o que é música independente; e qual o papel das rádios na promoção da diversidade cultural. Após essa compreensão, foi feita uma visita técnica a uma emissora educativa local.

16. Abreviação do termo "Jabaculê,", comum na indústria musical para denominar a prática do pagamento a emissoras de rádio ou TV pela execução de determinada música. (N.E.) 
VI - Na sexta etapa, os alunos produziram uma história contada através de fotografias. A atividade se transformou em um pequeno vídeo, contendo imagens sequenciadas e sonorizadas a partir do conhecimento aprendido nas primeiras oficinas.

3. Durante as oficinas, os alunos foram estimulados a produzir fotos, textos e análise das músicas de que mais gostam, reunindo esse conteúdo de maneira significativa no Myspace.

4. Ao término das oficinas, foram orientados a continuar a produção de conteúdos por conta própria, por um mês.

\section{RESULTADOS}

Os resultados obtidos mostraram que os jovens possuem grande capacidade de expressão, quando expostos a situações nas quais são instigados a utilizar as linguagens midiáticas para produzir mensagens. Em todos os exercícios sobre características musicais e sonoplastia, notou-se uma imensa facilidade de compreensão, bem como a aceitação dos alunos em relação ao assunto. Ainda nas atividades envolvendo música, os estudantes reconheceram a preferência que davam, de modo "inconsciente", ao ritmo norte-americano em relação às produções nacionais, alegando que essas eram bem mais modernas e atuais, portanto, melhores.

As discussões também possibilitaram uma compreensão maior acerca dos produtos ofertados pela mídia. Através de depoimentos, os próprios jovens notavam o acorrentamento ao universo criado e rotulado pelas grandes produtoras, seja na televisão, no rádio, seja até mesmo no cinema.

Percebeu-se que a televisão, principalmente a Rede Globo, tem grande participação na formação da identidade e opinião dos jovens. Dessa forma, quando questionados sobre algo, a conversa se limitava normalmente ao campo de experiência transmitida por essa emissora e pelas emissoras radiofônicas comerciais mais conhecidas na cidade. Porém, no momento em que foram apresentados a outra realidade, por meio da visita técnica à rádio educativa, observou-se o interesse e, principalmente, a curiosidade em aprender sobre o novo. A partir desse momento, os estudantes começaram a observar a produção de outros veículos, subestimando-os menos.

Com a experiência do rádio, foi possível constatar o potencial pedagógico dessa ferramenta na educação. No processo de locução, observou-se que os alunos passaram a prestar mais atenção em seus próprios erros, tanto na atividade individual quanto na atividade realizada em grupo. O erro, seja ortográfico, seja de pronúncia, foi sempre rapidamente percebido e corrigido por eles. Durante as entrevistas, observou-se a diminuição da timidez de cada um.

Ao escutar o programa produzido por eles, nota-se a capacidade de transformação do aprendizado em algo concreto, envolvendo desde os gêneros musicais escolhidos até a formatação do texto, passando pela expressão da locução e pelas estratégias adotadas ao pensarem na relação do programa com o público. 
comunicação \& educação • Ano XVII • número 1 • jan/jun 2012

Sobre o estudo com imagens, destaca-se o fato de aprendem rapidamente a linguagem fotográfica. Na reflexão e análise das imagens publicitárias, a participação foi unânime e surpreendente pelas diferentes interpretações apontadas.

Na etapa de produção da fotoestória, notou-se que a criatividade e a liberdade para criação possibilitaram aos jovens uma ampliação de horizontes, indo além da reprodução e subordinação. É importante ressaltar que a liberdade conquistada por eles ao longo das oficinas não desorganizou a produção do vídeo.

Sem perceber, os jovens criaram certa intimidade com a plataforma Myspce, de modo que as análises das fotografias se transformaram em sínteses de tudo aquilo que aprenderam nas oficinas. Já sobre o período de produção independente, ressalta-se que os jovens possuem dificuldade em trabalhar de maneira livre, ou seja, sem serem cobrados de alguma forma.

\section{CONSIDERAÇÕES FINAIS}

$\mathrm{O}$ estudo indicou que o ensino das linguagens midiáticas pode ser considerado uma rica experiência, se trabalhado e praticado no contexto da escola, pois, além de contribuir para a formação crítica, o aprendizado sobre os meios e suas linguagens possibilita a reflexão e o desenvolvimento da expressão nos jovens.

Em contato com os alunos participantes do projeto, foi possível perceber que a escola ainda tem muito a melhorar em relação às metodologias de ensino. Os alunos em pleno Ensino Médio possuem grande dificuldade para se expressar. O universo escolar, hoje, ainda se restringe ao mundo das reproduções, em que o aluno torna-se agente passivo, refém de ordens em seu próprio aprendizado.

A cultura das sociedades contemporâneas está intimamente ligada à mídia e ao uso dos meios para estabelecer comunicação. A escola, portanto, enquanto formadora, deve efetivamente proporcionar uma abordagem crítica em relação às mídias, pois, como ficou demonstrado na pesquisa, os alunos aprendem com muita facilidade e demonstram interesse sobre a linguagem dos meios.

Entretanto, para que atividades como essa se concretizem no ambiente escolar, ainda há um longo caminho a ser percorrido, incluindo a formação de professores, a inclusão da disciplina no currículo escolar e a produção de materiais e metodologias de ensino pautadas na mídia-educação.

\section{REFERÊNCIAS BIBLIOGRÁFICAS}

BELLONI, Maria L. O que é mídia-educação. Campinas: Autores Associados, 2001.

BUCKINGHAM, David. The media literacy of children and young people: a review of the research literature on behalf of Ofcom [A media literacy de crianças e jovens: uma revisão da literatura de pesquisa em behalf of Ofcom]. Londres: Office of Communications, 2005. 
BUCKINGHAM, David. Media education: literacy, learning and contemporary culture [Educação mediática: literatura, aprendizado e cultura contemporânea]. Cambridge: Polity Press, 2003.

CALDAS, Graça. Mídia, escola e leitura crítica do mundo. Educação e Sociedade, Campinas, v. 27, n. 9, jan./abr. 2006.

DIDONÉ, Iraci. M.; SOARES, Ismar O. O jovem e a comunicação. São Paulo: Edições Loyola, 1992.

SCHAFER, R. Murray. O ouvido pensante. São Paulo: Fundação Editora da Unesp, 1991.

SIQUEIRA, Alexandra B. de. Educação para a mídia: da inoculação à preparação. Educação \& Sociedade, Campinas, v. 29, n. 105, p. 1043-1066, set./dez. 2008.

TACCA, Fernando de. Imagem fotográfica: aparelho, representação e significação. Psicol. Soc. [on-line]. 2005, v. 17, n. 3.

TROTTA, F. Música e mercado: a força das classificações. Contemporânea Journal of Communication and Culture, v. 3, n. 2, 2006. 